\title{
The BIM revolution: a literature review on rethinking the business of construction
}

\author{
C. Allen \& W. Shakantu \\ Department of Construction Management, \\ Nelson Mandela Metropolitan University, South Africa
}

\begin{abstract}
In Joseph Schumpeter's Theory of Economic Development, the innovatorentrepreneur brings about disturbance to the equilibria through 'a process of creative destruction: technological and organisational innovations' that realign the new reality. Contrary to other industries that drive the world economy, the construction industry still operates at the level of a craft industry, which leads to immensely inefficient practices including the generation of massive amounts of waste. This is not only detrimental to the cost of the final product but is also unsustainable from a commercial as well as environmental perspective. Furthermore, the business of construction is seen as a high risk environment and is characterised by the lack of cooperation, limited trust and ineffective communication between various members of the project team which has led to non-productive work, contractual disputes and adversarial working relationships. As "communications provide the foundation for interaction that sustains cooperation in an organisation", the link to how organisations are structured to deal with the arrival of digital information within the construction industry, in the form of building information modelling (BIM), will be critical in improving delivery results on projects. This study of the literature identifies a rethinking of the way the business of construction will be structured and projects delivered. It highlights that a far more efficient way of delivering projects to the market place is evolving and that a process is already underway that will completely reshape the business of construction. By determining how BIM, the business process reengineering tool, is used as the platform upon which the project delivery process is changed, a model for the construction business of the future can be created, a digital revolution for the construction industry.

Keywords: BIM, communication, business process re-engineering, information management, integrated project delivery (IPD), lean production.
\end{abstract}




\section{Introduction}

Construction is characterised by the lack of cooperation, limited trust and ineffective communication between various members of the project team which has led to non-productive work, contractual dispute and adversarial working relationships on many projects. The end result of this environment is that projects are delivered late, over budget and from a user perspective, not to the clients' satisfaction. Furthermore, the business of construction is seen as a highly inefficient, high risk environment within an industry that needs to improve its competitiveness. To quote Patrick MacLeamy, chairman and chief executive officer of Hellmuth, Obata, and Kassabaum (HOK), an internationally respected multidisciplinary consultancy: "People are paying too much for their buildings, and the buildings are just not that good" (Miller et al. [1]).

There are many causes of this, not least a process that has changed little over the last two centuries, but chief amongst these is communication amongst project team members and the organisations they represent, which is the most significant inhibitor to successful project delivery. As has been highlighted in 'The impact of Building Information Modelling: Transforming Construction' (Crotty [2]), the inability of project teams to effectively communicate the endlessly updated and revised information created for complex projects results in adversarial relationships developing. This is reaffirmed in Emmitt and Gorse's [3] Communication in Construction teams research, with the 'nature of interaction affecting the strength of relationships between the actors'. As a result of this, numerous coordination issues arise which cause delay to projects, increase budgets through rework and scope change and increasingly lead to projects being rushed to completion. This then ultimately results in sub-standard workmanship and factious working relationships between the multitudes of sub-contractors traditionally employed to 'make it happen', management and the client.

As Evans and Wurster [4] note in Blown to Bits: How the new economics of information transforms strategy, 'information and the mechanisms for delivering it are the glue that holds together the structure of businesses'. Within construction, this has been further developed in a number of UK government-led reports which have "consistently drawn attention to the difficulties caused by the organisational systems in which construction teams operate" [3]. As "communications provide the foundation for interaction that sustains cooperation in an organisation" (Martin [5]), the link to how organisations are structured to deal with the arrival of digital information in the construction industry, in the form of building information modelling (BIM), will be critical in improving delivery results on projects. However, as business management practices have changed little over the last century, never mind the last 20 years of the digital revolution, the construction industry finds itself at a crossroads in terms of its future development. In the words of Jeffrey Beard et al. (SDRCPC [6]), "the past focus of the construction industry was upon rules rather than results, and on means and methods rather than on performance. [We need to] shift the emphasis from a fragmented approach to a combined effort in support of the owner's objectives." 


\subsection{The BIM revolution}

In Joseph Schumpeter's 1912 Theory of Economic Development, the innovatorentrepreneur brings about disturbance to the equilibria through 'a process of creative destruction: technological and organisational innovations' that realign the new reality" (Rosegger [7]). Contrary to other industries that drive the world economy, the construction industry still operates at the level of a craft industry, which leads to immensely inefficient practices including the generation of massive amounts of waste. This is not only detrimental to the cost of the final product but is also unsustainable from a commercial as well as environmental perspective. In addition, a convoluted procurement process sees a myriad of unrelated consultants, contractors and specialist sub-contractors bidding individually for lowest cost work based on incomplete information (Lepatner [8]). This further exacerbates the problem through wasted expenditure when companies do not win or by driving the bid cost down to such a level that the only way to make money is to claim, claim, and claim!

Revolution: "A dramatic and wide-reaching change in conditions, attitudes, or operation" (OED [9]). Taking a 'Schumpeterian' innovation such as BIM, it could be argued that it may be that through a radical new technology such as this, one could 'attack' existing construction industry equilibrium, thereby creating the possibility of achieving not only a better information platform from which to communicate the constant change but also to evolve the delivery mechanisms required to create a more sustainable business model. The potential is there for BIM to be the revolutionary change agent in the business of construction by facilitating a less adversarial and more efficient delivery process through the implementation of an information transformation which will have profound implications not only on how project teams are constructed but also how the 'other recognised functions in an organisation' (Smallwood [10]) are managed.

This at a time when companies in the Architectural, Engineering and Construction (AEC) industries are focused on finding ways to do more with less, within an increasingly competitive global marketplace, in order to remain competitive and in business. It has been shown that "interventions aimed at improvements along multiple 'strategic' dimensions such as time, cost, quality, satisfaction and product innovation" (Kettinger and Teng [11]) have the greatest potential to provide the returns envisaged to make companies competitive and create growth in the long term. When viewed as not merely a cost cutting exercise, with implementation that is more holistic in nature, it may be creating the opportunity for propulsive growth to occur within these organisations. This will, in itself, create pressure on other likeminded organisations to also change the way they go about their business, creating a contagion effect that will ripple through the supply chain.

\section{Rethinking the business of construction}

We live in an age of change, one not measured in years but in days or even hours, as the digital revolution of the information age propels all aspects of life forward 
at an increasingly faster rate. Yet, within this environment, we find pockets of life where businesses continue to exist in a time warp, stuck between the old order of the industrial revolution with its craft based processes and the modern, just-intime, on-demand, computer driven existence. H. Lee Martin makes the case for the use of "Darwin's Theory of Organic Evolution" as the basis for business to evolve their ways of working as they will otherwise face the prospect of failure as they are bypassed by more competitive organisations. "Technology is the driving force that causes change" [5] whilst the "competitive economy is the environment that imposes natural selection". When we look at the construction industry from this viewpoint, we are constantly made aware of the lack of evolution within it and the seemingly inevitable likelihood of organisations becoming obsolete overnight. As Todd Papaioannou, the chief technology officer of Splunk states, "Over the next decade, companies who leverage, monetise and compete on the data will be the companies that win" (Green [12]) whilst those in construction still grapple with paper based drawings "to record design and fabrication information, instead of digital object-based product models" (Eastman and Sacks [13]).

Hammer and Champy [14] from the radical school state in their seminal work Reengineering the Corporation that "the fundamental rethinking and radical redesign of business processes to achieve dramatic improvement in critical contemporary measures of performance such as cost, quality, service and speed" are the only way for organisations to evolve and adapt in order to grow, prosper and survive. "The Digital economy is fundamentally transforming the way we live and work" and it is "essential therefore that organisations, academia and individuals are prepared to adjust to potentially radical changes" (Philp and Thompson [15]). As a result, greater attention is being paid to Business Process Management strategies first evident in the 1980s in manufacturing, the financial services and retail sectors of the economy. Using management concepts taken from other industries that have modernised their delivery mechanisms, the "theory and rhetoric Business Process Re-engineering (BPR) is concerned with' provide for 'step change rather than incremental improvement; revolution, not evolution' (McGeorge and Zou [16]). Construction companies, particularly those that are listed, are looking to achieve between 15 and $20 \%$ return on shareholder capital. However, many of these self-same companies are only pricing in margins of 3$5 \%$ on project costs in order to remain competitive at tender stage. These tight margins therefore need to be converted into higher returns which can, in the long run, only be achieved through a combination of efficient working practices, reduced wastage (leading to an overall lower build cost) and completion ahead of schedule.

\subsection{BIM}

Research and discussion into the potential of Building Information Modelling/Management (BIM) as a tool to assist in changing the way projects are delivered and thereby provide a means through that to change the adversarial relationships between parties to a more cohesive and productive unit, have been ongoing since the release of the Latham report (1994) and Rethinking Construction (1998). However, although there are a number of books (BIM 
Handbook, 2011; The Commercial Real Estate Revolution, 2009; Transforming Construction, 2012; Partnering in the Construction Industry, 2006) and articles in construction related magazines, white papers and online blogs (McGraw Hill Construction Smart Market report, 2009 and 2012; CIB, 2009; Building magazine, 2001-2012; AECbytes, 2007-2012 and Building Design+Construction, 20112013) that have looked into the wider implications of the use of the technology as a tool for process change, research looking at BIM potentially being a catalyst for industry change have been neglected.

The 2009 McGrath-Hill Construction report [17] identified BIM 'as a potentially transformational approach to design and construction' and in the 2012 Smart Market report they further concluded that "New technologies gain traction when their benefits are meaningful and sustainable for users" (McGrath-Hill [18]). With industry adoption of the technology in the United States having risen from $28 \%$ in 2007 to $71 \%$ in 2012 , there appears to be an overwhelming agreement that this 'business solution' involving multiple value-chain members is beneficial to the bottom line. "BIM is a bit about software but more about the parties coming together to collaborate" (Sweet [19]). Furthermore, the United Kingdom (UK) government decision to make "the use of BIM mandatory on all public sector projects from 2016" (Kumar [20]) has focused the attention of both the design and construction sectors on the technology and more importantly on the process protocols and standards that are a fundamental aspect of the use of BIM. This will in all probability lead to a higher level of standardisation in components and the way information is delivered between project participants. To quote Paul Morrell, United Kingdom Government Chief Construction Advisor, "everybody is on a common platform so within a digital environment (which is one part of BIM) you all have access to the same data' (Healy [21]). Already we are seeing specialist suppliers producing Level 3 models for BIM applications in a number of formats, including the internationally recognised IFC. These 'volumetric models' include all the required components to make up the modelled section including the likes of Thermal, Structural and Acoustic performance information. Product literature is also available as a linked document to the model items in formats applicable to the facilities management software packages (Molloy [22]).

\subsection{Digital information revolution}

How will the construction industry respond to the capability of building with almost perfect digital information and the likely change in how business is carried out? In 'Techonomics: The Theory of Industrial Evolution' (Martin [5]) makes reference to the importance of "perfect information" in facilitating the probability of becoming a great decision maker, focusing in on four key characteristics: 'Accuracy, Timeliness; Cost and Completeness'. Unfortunately, in the construction industry information production is currently confusing and sometimes unnecessary. It is also not structured properly, poorly coordinated and/or difficult to locate which inevitably leads to cost escalation of $20-25 \%$ on project delivery costs. Should BIM provide for the possibility of perfect information, then we are looking at a paradigm shift in the business of construction, with the implications of this being similar in nature to those 
experienced by businesses in the retail and commercial sectors with the advent of personalised computers and the internet in the 1980s. This technology was a disruptor to traditional business models and created a revolution in the way business was conducted through a combination of 'perfect information' leading to transaction cost reduction. Business strategy has 'always been premised on assumptions about technology' Henderson (1975) and the ability of the value chain to 'economize on the transaction costs' Porter (1980). Both of these aspects were premised on the transaction costs being the key enabler of business. But the two key components of transaction costs, communication and processing of information, have been falling dramatically in other industries for over 20 years without much focus being paid to them in the construction industry. BIM is a tool that allows us to do this by providing clarity in the process, improving efficiencies and thereby cost and time savings in the delivery process. If current business success 'depends on the ability to invest in relevant digital capabilities that are well aligned with strategy' (Catlin et al. [23]), then BIM becomes paramount to our ability to create leaner, more efficient operational entities.

Furthermore, previous changes in other industries had occurred over the past one hundred years whereby the craft system in use as the main means of production had been superceded by industrial mass production and subsequently lean production methodologies taken from the thinking of Deming [24] and the Toyota Motor Corporation (Liker [25]). A combination of these factors has made other industrial processes far more efficient at delivering products to the market place and of evolving new products for their ever expanding customer base. However, in construction, productivity is an industry wide problem [13], (Teicholz [26]; Economist Intelligence Unit (EIU) [27]) that can be enhanced "by greater adaption of value-based procurement and innovative industry technologies". As some of these practices have yet to gain general acceptance in the construction industry, including 'outsourcing, JIT manufacturing/delivery, mass customization, globalisation and lean organisation' [13], this therefore raises the question, could the same be about to occur in construction? It has been "shown that off-site production of building components has become significantly more labour productive" and "that a major component of the productivity enhancement in manufacturing has been realised from the application of information technologies" [13], which brings into focus the "I" in BIM and the data at the heart of the digital revolution. Because data can be stored it can be connected and analysed, enabling clients and construction companies to better understand the causes of the current productivity gap, enabling the implementation of tools and strategies to address this. If the "construction industry can apply the reengineering concept or a derivative of this concept this will be a major contributor to the advancement of the construction sector' [16]. Waste is occurring and implementing strategies to eliminate it will enable a more horizontal structure and revised business strategy that knows how to accommodate collaboration and competition simultaneously!

\subsection{Reengineering culture}

The construction industry still has challenges in structure to overcome in order to fully embrace this model. "Improving productivity demands a prescription of 
collaboration that supports a culture of shared risks and rewards across the value chain and a willingness to think and act beyond the context of individual projects" (EIU, 2015). The inability of project teams to trust one another due to historical legacies passed down from one generation to the next have conspired to reduce the benefits that may accrue and have increased the barriers to greater adoption as a result. As has been clearly identified, this 'ultimately colours their ability to transfer knowledge and appropriate task-based information' [3], which leads to delay and cost overruns on even the most efficient project sites. So how to overcome this? As the authors of the 2009 Constructing Excellence report concluded, "we believe that the era of client-led change is over, at least for the moment, and that it is now time for the supply side to demonstrate how it can create additional economic, social and environmental value through innovation, collaboration and integrated working" (Wolstenholme et al. [28]). It will require companies to re-evaluate the way they manage their business and the 'basic procedures by which managers make decisions' (Goldratt [29]). "The journey to digital maturity requires a whole-hearted commitment from a company's leadership and a sustained investment in people, capabilities, technology and cultural change" [23]. This will require that companies adopt alternative thinking to that currently seen as the standard by which to measure their performance, a delivery process that "unambiguously describes "what we do and how we do it" using a single communications tool that can 'mesh' with similar technology in other organisations to form a 'flexible, polymorphous, fuzzy edged extended enterprise' (Smith and Fingar [30]). The Technology Strategy Board has identified that where a 'consistent framework is enacted', as in the UK, "this will enable UK practices and global practices to collaborate to a far greater degree" [19]. This also highlights, therefore, that government policy can shape an industry and champion a process of change which benefits the industry as a whole.

Furthermore, as has been demonstrated in Improving Construction Planning through 4D planning (Allen and Smallwood [31]), BIM models are also immensely useful in the delivery of projects from a time management perspective through 4D planning as well as for just in time delivery, which further enhance the use of lean production methods currently being employed in other manufacturing environments. "Lean and BIM have major synergy effects, which are increasingly being explored and implemented by leading practitioners" (CIRIA [32]), so construction companies will be able to use their new found skills using BIM in the form of virtual design and construction (VDC) models, "an application used to visualise, analyse and evaluate project performance" [27], to realise even greater gains in aspects such as procurement and health and safety, removing complex and dangerous onsite activities to the controlled manufacturing environment, further speeding up the delivery process. Add to this the increased ability to coordinate the design within the digital environment through cloud based systems such as the one Ewing Cole now uses which is an "internal "cloud" allowing team members to work on BIM through central servers' or Thornton Tomasetti's use of 'BIM to produce digital fabrication drawings' (Cassidy and Gregorski [33]), which will furthermore increase the efficiency of construction projects, saving costs and improving on the deliverables highlighted as being at the forefront of the poor image the industry currently has. It has been shown "that off-site production of 
building components has become significantly more labour productive, in contrast to related on-site activities" [13].

This process needs to provide additional benefits which Chan and Cooper [34] allude to in Constructing Futures, 'any discussion about the future invariably evokes thinking about the issue of sustainability', which is an area BIM can play a leading role in terms of business efficiency as well as through better simulation of building performance, as described by Kim and Woo [35] "energy performance analysis can be improved significantly using a BIM-based energy simulation model that integrates detailed HVAC data directly extracted from BIM". The value add is further heightened by research published by the RICS at COBRA 2012 [36], where it was estimated that 'the construction industry in the UK produces up to one third of all waste to landfill.' Ogunbiyi et al. [37] emphasise that through the use of lean tools and techniques, 'waste reduction' can lead 'to value generation and increased productivity' which links through to sustainability through the use of techniques such as 'JIT, visualisation tool' and the 'elimination of unnecessary processes'. By furthering the ability of all project teams to create more from less including the improved performance of facilities through simulation modelling, improving on the performance of buildings and reducing in both monetary as well as resources terms, the impact of buildings on our future, BIM has the potential to become the key to the unlocking of the shackles on industry wide transformation. By using integrated tools such as clash detection as well as in-built features like automated take-off tools that synchronise with standard procurement packages, the business process aspects can also be addressed directly in the digital realm, saving groves of trees as a result, a truly sustainable business model!

\subsection{Management processes}

Are design teams and contractors working any closer together or communicating more effectively and are the adversarial relationships the industry is well known for becoming less noticeable with this increased uptake in BIM implementation? According to the 2013 AECOM Blue Book - Collaboration: Making cities better [38], apart from New Zealand, the whole world currently operates in an 'adversarial' rather than a 'collaborative' culture, with Australia ranking 1st, despite it reportedly seeing an escalation in BIM uptake! Possibly this is an indictment on current working methodologies and an even greater reason why change needs to occur. It has been shown that where BIM has been implemented, project teams are already identifying benefits from having started to work in BIM [33] with comments such as "Once a team becomes proficient in the BIM process, we see better margins for projects completed ..." and "other benefits of a BIM workflow are not so easily quantifiable, but they are real enough to give us confidence that BIM is paying off'. In describing the impact of technology implementation in other business process reengineering, Thomas Davenport from the Conservative School noted that a revolutionary approach that uses IT and human resources management will dramatically improve business performance [39] which will inevitably win over the majority as has happened in the US and is happening in the UK where 'the UK's embrace of BIM was helping British firms 
win work overseas' [19]. This then ultimately leads to the competitive needs of an industry shaping the future delivery processes employed.

It can thus be asked whether this change should be led by a change in the type of contract and team employed at the commencement of the project, one which has a far greater emphasis on an equitable share of the risk between client and service provider. Already we are seeing leading client groups including the general services administration (GSA) and Sutter Health, a not-for-profit community health care provider based in the United States (US), changing the way they contract projects to spread the risk and create a 'trust-based integrated project'. The CIB have already delivered a white paper on Integrated Design and Delivery Solutions (IDDS) [40] in which they state that "there is unquestionably significant scope for IDDS to improve the delivery of value to clients and stakeholders, whilst simultaneously driving down cost and time to deliver operational constructed facilities". The Chartered Institute of Building (CIOB) has also released a 'Code of Practice' [41] which highlighted the purported benefits of using 'Partnering' as a way to complete projects successfully and to the satisfaction of clients. Add the extensive use of Integrated Project Delivery (IPD), particularly in the United States, and you have the makings of a fundamental shift in project delivery mechanisms. This should in itself lead to a change in the way that projects are financed and how project teams are put together. The need to work with likeminded professionals who subscribe to a similar level of professional integrity as well as an ability to manage the commercial risk appropriately will create a far less adversarial working environment in which to deliver new projects. "Collaborating through process management..., will be a source of considerable competitive advantage over the next decades" [30].

With the emergence of development specifications for the transfer of information between the various design models as well as for onward transfer to the contractor (Bedrick [42]), a more transparent and open communications platform has been established whilst "the integration of the processes of planning, design, construction installations, products and materials selection and facilities management/maintenance will result in a substantial reduction in construction costs" (Egan [43]). However, this enthusiasm should be tempered by the fact that as Richard Saxon of the Construction Industry Council noted, 'no firm will invest in R\&D if it raises overheads and makes it less competitive in the short term' [19] whilst Davidson [44] correctly points out that 'as long as there is no economic impact, there is no innovation'. Project teams that focus on improving the deliverable project for less money in a faster time through reductions in 'inventory', 'producing zero defects' and 'designing based on system process' (Morgan [45]), as is the case with BIM, maximise on the profit margin they will be guaranteed on the completion of the project bringing about higher levels of performance. "The use of BIM has led to improved profitability, reduced costs, better time management and improved customer-client relationships" (Azhar et al. [46]). 


\section{Conclusion}

Construction companies need to improve their processes to remain competitive in an increasingly globalized market. 'Reducing construction cost and time and increasing output quality is achievable by re-engineering how major construction business processes are conducted' (Mohamed and Tucker [47]). BIM equates to being a disruptor of the current equilibrium construction businesses operate within, enabling re-engineering of the 'cooperative culture between industry professionals' leading to the likelihood of further consolidation of the professional's into multidisciplinary entities and the potential for master builders to emerge for a digital age. "With all information about a building design being available digitally, further automation in design, engineering, fabrication and erection are all possible and expected" [13]. As David Philp comments in the BIM2050 report [15]: "The Digital economy is fundamentally transforming the way we live and work" before going on to state that it is "essential therefore that organisations, academia and individuals are prepared to adjust to potentially radical changes". The emergence of this phenomenon within the construction industry will lead organisations towards a more integrated process of design, procurement, construction and facilities management within a single contract delivery document and information hub, a digital revolution for the construction industry.

\section{References}

[1] Miller, R., Strombom, D., Iammarino, M., and Black, B., The Commercial Real Estate Revolution, John Wiley \& Sons, New Jersey, 2009.

[2] Crotty, R., The Impact of Building Information Modeling: Transforming Construction, Spon Press, London, 2012.

[3] Emmitt, S. and Gorse, C., Communication in Construction Teams, Taylor \& Francis, London, 2007.

[4] Evans, P. and Wurster, T., Blown to Bits: How the new economics of information transforms strategy, Harvard Business School Press, Boston, 2000 .

[5] Martin, H., Techonomics: The Theory of Industrial Evolution, Taylor Francis, New York, 2007.

[6] San Diego Regional Construction Procurement Committee (SDRCPC), Top 4 Issues Final White Paper, San Diego Regional Construction symposium, San Diego State University, August 11, 2010. www.Top4issues.com

[7] Rosegger, G., The Economics of Production and Innovation: an industrial perspective, Butterworth-Heinemann, Oxford, 1996.

[8] Lepatner, B., Broken Buildings, Busted Budgets, The University of Chicago Press, Chicago and London, 2007.

[9] Oxford English Dictionary, 10th ed. rev, Oxford University Press, 2001.

[10] Smallwood, J.J., The Practice of Construction Management, Acta Structilia, 13 (2), 62-89, 2006. 
[11] Kettinger, W. \& Teng, J., Aligning BPR to Strategy, Long Range Planning, 31 (1), 93-107, 1998.

[12] Green, J., Finance Chiefs go from counting beans to planning, Business Report, Friday, May 23, 2014.

[13] Eastman, C. and Sacks, R., Relative productivity in the AEC Industries in the United States for On-Site and Off-Site Activities, Journal of Construction Engineering and Management, ASCE; July, 2008.

[14] Hammer, M. \& Champy, J., Reengineering the corporation: A manifesto for Business Revolution, Nicholas Brealey Publishing, London, 1993.

[15] Philp, D. \& Thompson N., BIM 2050, Construction Industry Council, 2014. http:/www.bimtaskgroup.org/wp-content/uploads/2014/09/2050Report.pdf

[16] McGeorge, D and Zou, P, Construction Management: New Directions $3^{\text {rd }}$ Edition, Wiley-Blackwell, New Jersey, 2013.

[17] McGrath-Hill Construction, The Business Value of BIM: Getting Building Information Modeling to the Bottom Line, New York, 2009.

[18] McGrath-Hill Construction, The Business Value of BIM: Multi-year trend analysis and user ratings, New York, 2012.

[19] Sweet, R., Reversing Babel, Construction Research and Innovation magazine, Vol 5, Issue 2, 2014.

[20] Kumar, B., Building Information Modeling: Road to 2016, International Journal of 3-D Information Modeling, 1 (4), 192-199, 2012.

[21] Healy, B., 'BIM - One year on ...', Evolution, Summer, p.3, 2012.

[22] Molloy, C. ed., Acheson \& Glover shaping change with BIM, Irish Building Magazine, Issue 3, 2014.

[23] Catlin, T., Scanlan, J. \& Willmott, P., Raising your digital quotient, McKinsey Quarterly, McKinsey \& Company, 2015.

[24] Deming, W., Quality, Productivity and Competitive Position, Massachusetts Institute of Technology, 1982.

[25] Liker, J., The 14 Principles of the Toyota Way: An Executive Summary of the Culture Behind TPS, University of Michigan, 2004.

[26] Teicholz, P., Labor-Productivity Declines in the Construction Industry: Causes and Remedies (Another Look), AECbytes, Viewpoint \#67 (March 14, 2013). http://www.aecbytes.com/viewpoint/2013/issue_67.html

[27] The Economist Intelligence Unit, Rethinking productivity across the construction industry: The challenge of change, The Economist, 2015. http://www.economistinsights.com/technology-innovation/analysis/ rethinking-productivity-across-construction-industry

[28] Wolstenholme, A., Austin, S., Bairstow, M., Blumenthal, A., Lorimer, J., McGuckin, S., Rhys Jones, S., Ward, D., Whysall, D., Le Grand, Z., Guthrie, W. \& Davies, R., Never waste a good crisis: a review of progress since Rethinking Construction and thoughts for our future, London: Constructing Excellence, 2009.

[29] Goldratt, E., The Haystack Syndrome, North River Press, New York, 1990.

[30] Smith, H. \& Fingar, P., Business Process Management - The $3^{\text {rd }}$ Wave, Meghan-Kiffer Press, Tampa, 2003. 
[31] Allen, C. \& Smallwood, J., Improving construction planning through 4D planning, Journal of Engineering, Design and Technology, 6(1), 7-20, 2008.

[32] CIRIA, Implementing Lean in construction: Overview of CIRIA's guides, London, 2013. www.ciria.org/service/lean

[33] Cassidy, R. \& Gregorski, T., BIM finally starting to pay off for AEC firms, Building Design+Construction, July, 2012. http://www.bdcnetwork.com/ bim-finally-starting-pay-aec-firms

[34] Chan, P. \& Cooper, R., Constructing Futures: industry leaders and futures thinking in construction, Wiley-Blackwell, New Jersey, 2011.

[35] Kim, S. \& Woo, J-H., Analysis of the differences in energy simulation results between building information modeling (BIM)-Based simulation method and the detailed simulation method: Proceedings of the 2011 Winter Simulation Conference, Phoenix, AZ, 11-14 December 2011.

[36] RICS, Reducing Construction Waste to Landfill in the UK, COBRA, 2012.

[37] Ogunbiyi, O., Oladapo, A. \& Goulding, J., An empirical study of the impact of lean construction on sustainable construction in the UK, Construction Innovation, 14 (1), 88-107, 2014.

[38] Davis Langdon, Blue Book 2013 - Collaboration: Making Cities Better, AECOM Australia, 2013. www.aecom.com

[39] Davenport, T., Process Innovation: Reengineering Work Through Information Technology, Harvard Business School Press, Boston, 1993.

[40] CIB, White Paper on IDDS - Draft, 24 September 2009. http://heyblom.websites.xs4all.nl/website/priority_themes/CIB_IDDS_Wh ite_Paper.pdf

[41] Bennett, J. \& Peace, S., Partnering in the Construction Industry: Code of Practice for Strategic Collaborative Working, Butterworth-Heinemann, Oxford, 2006.

[42] Bedrick, J., A Level of Development Specification for BIM processes, AECbytes Viewpoint \#68 (May 16, 2013). http://www.aecbytes.com /viewpoint/2013/issue_68_pr.html

[43] Egan, J., Accelerating Change: Consultation Paper by Strategic Forum for Construction, London: HMSO, 2002.

[44] Davidson, C., Editorial: Innovation in Construction - before the curtain goes up, Construction Innovation, 13 (4), 344-351, 2013.

[45] Morgan, J., Creating lean corporations: Reengineering from the bottom up to eliminate waste, Productivity Press, New York, 2005.

[46] Azhar, S., Khalfan, M. \& Maqsood, T., Building information modelling (BIM): now and beyond, Australasian Journal of Construction Economics and Building, 12 (4), 15-28, 2012.

[47] Mohamed, S. \& Tucker, S., Options for applying BPR in the Australian construction industry, International Journal of Project Management, 14 (6), 379-385, 1996. 